\title{
An external, oversized, porous polyester stent reduces vein graft neointima formation, cholesterol concentration, and vascular cell adhesion molecule 1 expression in cholesterol-fed pigs
}

\author{
Gianni D. Angelini, FRCS \\ Clinton Lloyd, FRCS \\ Ray Bush, PhD, \\ Jason Johnson, MSc \\ Andrew C. Newby, PhD
}

\footnotetext{
From the Bristol Heart Institute, Bristol Royal Infirmary, Bristol, United Kingdom. Supported by the British Heart Foundation. Received for publication Feb 7, 2002; revisions requested April 4, 2002; revisions received, May 28, 2002; accepted for publication June 5, 2002.

Address for reprints: Andrew Newby, PhD, Bristol Heart Institute, Bristol Royal Infirmary, Bristol BS2 8HW, United Kingdom (E-mail: A.Newby@bris.ac.uk).

J Thorac Cardiovasc Surg 2002;124:950-6

Copyright $\odot 2002$ by The American Association for Thoracic Surgery

0022-5223/2002 \$35.00+0 $\quad \mathbf{1 2 / 1 / 1 2 7 0 0 4}$

doi: $10.1067 / \mathrm{mtc} .2002 .127004$
}

\begin{abstract}
Background: Reducing neointima formation and atherosclerosis are key goals in preventing late vein graft failure. Although pharmacologic and mechanical solutions have been proposed, the demonstration that these influence both aspects of vein graft pathology have been lacking. Supporting grafts externally with an oversized, highly porous polyester stent dramatically reduces neointima formation in normocholesterolemic pigs. However, its effects in the presence of hypercholesterolemia are unknown.
\end{abstract}

Methods: We compared wall thickening, cholesterol concentration, foam-cell formation, and the expression of the leukocyte adhesion molecule vascular cell adhesion molecule 1 after 3 months in stented and unstented saphenous vein interposition grafts into the carotid arteries of pigs fed cholesterol to cause modest hypercholesterolemia $(11.2 \pm 1.2 \mathrm{mmol} / \mathrm{L})$.

Results: Stenting reduced neointima formation from $5.6 \pm 0.4$ to $1.2 \pm 0.2 \mathrm{~mm}^{2}$ ( $\mathrm{n}=7 ; P<.00002$, paired $t$ test) and graft cholesterol concentration from $4.7 \pm 1.2$ to $2.1 \pm 1.3 \mathrm{mg} / \mathrm{g}$ wet weight $(P<.02)$. Foam cells were observed in unstented grafts (mean, $1.5 \% \pm 0.5 \%$ of all cells) but never in stented grafts. Vascular cell adhesion molecule 1 was strongly expressed in 53\% $\pm 8 \%$ of intimal and medial cells in unstented grafts but was weakly expressed in only $19 \% \pm 3 \%$ (n $=4, P<$ $.05)$ of stented grafts.

Conclusions: We conclude that external stenting with polyester favorably influences both neointima formation and early atherosclerosis, both of which are key aspects of vein graft disease, and that decreased expression of vascular cell adhesion molecule 1 is part of the underlying mechanism.

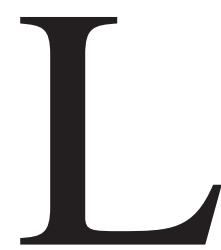

ate vein graft failure between 5 and 12 years after implantation occurs in as many as $50 \%$ of saphenous vein coronary artery bypass grafts and requires further intervention or surgical procedures. ${ }^{1}$ Late vein graft failure occurs as a result of atherosclerosis formation on a vessel wall previously thickened by smooth muscle cell hyperplasia. ${ }^{2}$ Reduction in vein graft thickening, neointima formation, and atherosclerosis are key goals in preventing late vein graft failure ${ }^{3}$; both pharmacologic and mechanical solutions have been proposed. Pharmacologically, intensive lipid-lowering therapy with statins reduces the appearance of new angiographically defined lesions in human vein grafts. ${ }^{4}$ Inhibition of vascular smooth muscle cell proliferation with antisense oligonucleotides decreased neointima formation in vein 
grafts. ${ }^{5,6}$ Decoy oligodeoxynucleotides against the cell-cycle regulator E2F also decreased cholesterol deposition in experimental studies ${ }^{7}$ and showed a promising effect on early clinical outcomes. ${ }^{8}$ Mechanically, it has long been thought that increased wall tension in the vein graft when exposed to arterial pressure is responsible for neointima formation. ${ }^{9}$ For this reason, efforts have been made to provide external support for the vein for a time after implantation. Supporting veins with a nonporous, expanded, polytetrafluoroethylene external stent was shown to decrease vein graft cholesterol uptake in cholesterol-fed rabbits, ${ }^{10}$ although such materials greatly increase neointima formation and reduce final lumenal size in both rabbit and pig vein grafts. ${ }^{11-13}$ In contrast, supporting pig vein grafts with a highly porous, oversized, polyester external support dramatically reduces neointima formation, ${ }^{14-16}$ and a clinical trial of this concept is ongoing. However, it is not known what influence external polyester stenting has on neointima formation or cholesterol uptake in the presence of hypercholesterolemia.

To investigate this directly, we placed saphenous vein interposition grafts into the carotid arteries of cholesterolfed pigs and measured vein graft dimensions and cholesterol content. Surrounding grafts with an oversized polyester support significantly reduced neointima formation. Graft cholesterol concentration and formation of foam cells was also reduced. To investigate the mechanism underlying this reduction, we measured the expression of the leukocyte adhesion molecule vascular cell adhesion molecule (VCAM) 1, which has recently been shown to be a key mediator of atherosclerosis formation. ${ }^{17}$

\section{Methods}

\section{Animals}

Studies were performed with Large White Landrace pigs, initially weighing 18 to $35 \mathrm{~kg}$, which received humane care according to the United Kingdom Home Office Animals Care regulations.

\section{Diet}

Twenty-two pigs received a commercially available powdered diet (BOCM) supplemented (by weight) with $2 \%$ cholesterol, $1 \%$ cholic acid (Sigma Chemicals, St Louis, Mo) and 10\% saturated fat (Atora suet, McDougalls Foods Ltd, Bedfordshire, United Kingdom). This mixture was prepared daily as a wet mash (equal measures of diet and tap water) and fed at a rate of $1 \mathrm{~kg}$ per pig per day ( $1.5 \mathrm{~kg}$ per pig $>35 \mathrm{~kg}$ in weight).

\section{Plasma Cholesterol Analysis}

Because not all pigs responded to the diet with an increase in plasma cholesterol level, animals were bled after at least 7 days on the diet. Blood was withdrawn from an ear vein, and plasma cholesterol was determined enzymatically (Olympus System Reagent, cholesterol, Olympus Diagnostica). Only animals that achieved a plasma cholesterol level of at least $8 \mathrm{mmol} / \mathrm{L}$ were included in the study to maximize the stimulus for graft cholesterol accumulation. Further plasma cholesterol determinations were done in these pigs at the time of graft harvest.

\section{Operative Procedures}

All animals underwent bilateral saphenous vein into carotid artery interposition grafting, as previously described. ${ }^{18}$ In brief, a $2-\mathrm{cm}$ segment of each common carotid artery was excised, beveling the cut ends obliquely to $45^{\circ}$. Saphenous vein, similarly beveled, was reversed and anastomosed end to end into the common carotid artery by using a continuous 7-0 Prolene suture (Ethicon, Inc, Somerville, NJ). As detailed previously, an 8-mm-diameter polyester locknit velour tube externally wound with polypropylene (Vascutek Ltd, Inchinnan, Renfrewshire, Scotland) was used to externally stent one of the grafts in each pig. The location (left or right) and order of performing the grafts was randomized between procedures. The tube, which was long enough to cover both anastomoses completely, was divided longitudinally along one side and gently insinuated around the completed graft. The tube was then reformed by using 3 silk ligatures.

\section{Harvest of Grafts}

Twelve weeks after implantation, the grafts were recovered. The grafts were re-exposed, checked for blood flow (patency), and then removed. One-centimeter segments of the proximal and distal carotid arteries were also sampled. Grafts were divided into 2 pieces. The cut end of one half was closed with fine suture to permit fixation with Carson's fixative at $100 \mathrm{~mm} \mathrm{Hg}$ pressure. The other portion was divided into several pieces and frozen in liquid nitrogen for preparation of frozen sections and chemical analysis. A portion of carotid artery adjacent to the graft and a piece of saphenous vein from the unoperated leg that had not been used during the operation were also frozen.

\section{Histologic Techniques}

Wax-embedded sections $(5 \mu \mathrm{m})$ were stained with hematoxylin and eosin or Miller's elastic van Gieson stain, as previously described. ${ }^{19}$ Vessel-wall dimensions were measured by means of computer-aided planimetry. ${ }^{14}$ The area enclosed by the endothelium defined the lumen, the area inside the internal elastic lamina defined the lumen plus neointima, and the area between the internal and external elastic lamina defined the media. Lumenal encroachment was defined as the percentage of the area enclosed by the internal elastic lamina occupied by the neointima. Lumenal, intimal, and medial perimeters and areas were computed by using the lumenal boundary and internal and external elastic laminae as delimiters, and the average intimal, medial, and total vessel-wall thicknesses were derived from the area and perimeter data for 5 sections from each graft, as detailed previously. ${ }^{14}$

Alternatively, $5-\mu \mathrm{m}$ frozen sections $(5 \mu \mathrm{m})$ were treated with a saturated solution of Oil Red O in propan-2-ol and counterstained with hematoxylin, and the percentage of cells positive for Oil Red $O$ was counted in 4 random $40 \times$ fields, which abutted the lumen and included the neointima. Immunocytochemistry for myeloid cells (macrophages) was conducted on serial sections by using the MAC-387 monoclonal antibody (Serotec Ltd, Oxford, United Kingdom), VCAM-1 by using the monoclonal antibody $10.2 \mathrm{C} 7,{ }^{20}$ or intercellular adhesion molecule (ICAM) 1 by using monoclonal antibody P19C7,21 which were generous gifts of Professor Dorian 

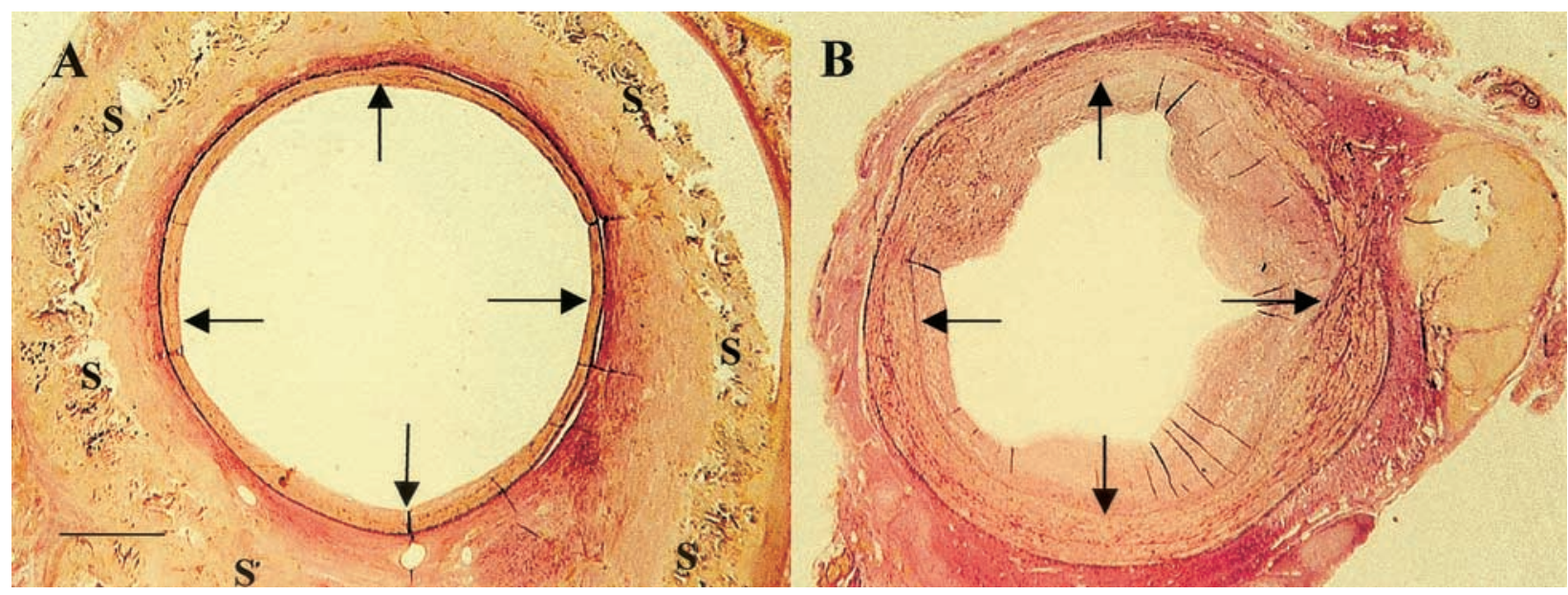

Figure 1. Effect of stenting on vessel-wall dimensions: A, van Gieson staining of a stented vein graft after 3 months; B, van Gieson staining of an unstented vein graft after 3 months. The intimal medial boundary is shown with arrows. The scale bar shows $500 \mu \mathrm{m}$.

TABLE 1. Effect of external polyester stenting on vein graft dimensions

\begin{tabular}{lccc}
\hline Parameter & Unstented graft $(\mathbf{n}=\mathbf{7})$ & Stented graft $(\mathbf{n}=\mathbf{7})$ & $\boldsymbol{P}$ value \\
\hline Intimal area $\left(\mathrm{mm}^{2}\right)$ & $5.6 \pm 0.4$ & $1.2 \pm 0.2$ & $<.00002$ \\
Medial area $\left(\mathrm{mm}^{2}\right)$ & $8.5 \pm 1.4$ & $1.8 \pm 0.4$ & $<.0005$ \\
Lumenal encroachment $(\%)$ & $39 \pm 5$ & $10 \pm 3$ & $<.0005$ \\
Intimal thickness $(\mathrm{mm})$ & $0.45 \pm 0.03$ & $0.16 \pm 0.02$ & $<.00001$ \\
Medial thickness $(\mathrm{mm})$ & $0.55 \pm 0.07$ & $0.16 \pm 0.04$ & $<.001$ \\
\hline
\end{tabular}

$P$ values were calculated with the paired Student $t$ test.

TABLE 2. Effect of external polyester stenting on vein graft cholesterol concentration

\begin{tabular}{lccc}
\hline Parameter & Unstented graft $(\mathbf{n}=\mathbf{7})$ & Stented graft $(\mathbf{n}=7)$ & $\boldsymbol{P}$ value \\
\hline Cholesterol concentration (mg/g wet weight) & $4.7 \pm 1.2$ & $2.1 \pm 0.3$ & $<.02$ \\
DNA concentration (mg/g wet weight) & $0.25 \pm 0.04$ & $0.22 \pm 0.04$ & $\mathrm{NS}$ \\
Cholesterol concentration (mg/mg DNA) & $18.8 \pm 3.0$ & $10.9 \pm 1.5$ & $<.05$
\end{tabular}

$P$ values were calculated with the Student $t$ test for paired data. Values are expressed as mean \pm SEM. NS, not significant.

Haskard (Cardiovascular Medicine Unit, Imperial College School of Medicine, Hammersmith Hospital, London, United Kingdom). Sections were fixed in ice-cold acetone and air dried. Endogenous peroxidase activity was blocked with hydrogen peroxide, and then the sections were treated with $20 \% \mathrm{vol} / \mathrm{vol}$ goat serum in phosphate-buffered saline. Sections were incubated overnight at $4^{\circ} \mathrm{C}$ with a 1:50 dilution of Mac387 or $12 \mu \mathrm{g} / \mathrm{mL} 10.2 \mathrm{C} 7$ antibody or the same concentrations of isotype-specific mouse $\mathrm{IgG}$ diluted in phosphate-buffered saline containing $10 \mathrm{mg} / \mathrm{mL}$ bovine serum albumin. Sections were then washed and incubated with a 1:200 dilution of biotinylated goat anti-mouse $\mathrm{IgG}$, followed by a 1:400 dilution of alakaline phosphatase-labeled ExtrAvidin. Color was developed with $0.05 \%$ Fast Red TR/Napthol AS-MX. Nuclei were counterstained with hematoxylin. For each vein studied, the number of VCAM-1-positive (red staining) cells was scored in 4 randomly chosen $0.25-\mathrm{mm}^{2}$ fields, which included the most intimal portion of the graft and was expressed as a percentage of the total number of nucleated cells.

\section{Measurement of Tissue Cholesterol Concentrations}

Segments of graft comprising the whole of the vessel wall (intima, media, and adventitia) and weighing about $90 \mathrm{mg}$ were ground to a fine powder in liquid nitrogen by using a pestle and mortar. Total lipid was extracted with chloroform/methanol ( $2: 1 \mathrm{vol} / \mathrm{vol})$, dried, and reconstituted in isopropanol for enzymatic determination of cholesterol, as described for serum above. The nonlipid residue of the samples was dried, and deoxyribonucleic acid concentration was determined fluorimetrically by using the method of Kissane and Robins. ${ }^{22}$ 


\begin{abstract}
Statistical Analysis
Values are shown throughout as the mean \pm SEM. Significance between groups was established by using the paired Student $t$ test after performing a $z$ score for skewness with a value of less than 2.5 for normally distributed data. Nonparametric data were compared with the Wilcoxon signed-rank test.
\end{abstract}

\section{Results}

Inclusion Criteria, Operative Success, and Production of Hypercholesterolemia in Pigs

Plasma cholesterol concentration in 13 pigs fed a commercial chow diet was $2.2 \pm 0.2 \mathrm{mmol} / \mathrm{L}$. A total of $22 \mathrm{pigs}$ were fed the cholesterol-enriched diet for at least a week, resulting in a mean plasma cholesterol level of $9.8 \pm 0.4$ $\mathrm{mmol} / \mathrm{L}$. Responses ranged from 3.2 to $22.1 \mathrm{mmol} / \mathrm{L}$, although the level achieved was stable within a particular animal (results not shown). Of the pigs, 11 achieved a cholesterol level of at least $8 \mathrm{mmol} / \mathrm{L}$ (approximately 4 times the normal level), and these were included in the study. Each of these pigs received an unstented graft in one carotid artery and a graft stented with an oversized, macroporous, polyester stent in the other. There were 2 operative deaths, leaving 9 pigs that completed the study. Of the 18 grafts harvested, one stented and one unstented graft in different pigs were occluded. The results from both grafts of these pigs were therefore excluded from analysis. Among the 7 pigs included in the final analysis, the cholesterol-rich diet caused an increase in plasma cholesterol levels from $2.3 \pm 0.1 \mathrm{mmol} / \mathrm{L}$ before feeding to $11.2 \pm 1.2 \mathrm{mmol} / \mathrm{L}(P$ $<.001)$ at the time of death 13 weeks later.

\section{Graft Neointima Formation}

Unstented grafts showed thickening of the media with disruption of the elastic layers, as previously described ${ }^{19}$; an extensive neointima with disorganized arrangement of cells was also formed (Figure 1, B). Stenting significantly reduced neointimal and medial size and medial disruption compared with that seen in unstented grafts (Figure 1, A, and Table 1). The neointimal cross-sectional area was reduced by $79 \%$, which led to a $74 \%$ decrease in encroachment of the neointima into the lumen. Medial cross-sectional area was also reduced by $79 \%$ in stented compared with control grafts.

\section{Tissue Cholesterol Concentration}

Stented grafts in cholesterol-fed pigs also had significantly reduced cholesterol concentrations (Table 2) compared with unstented grafts, either when this was expressed per wet weight or per milligram of DNA (ie, per cell). The concentration of cholesterol in the unstented grafts was approximately 4 times greater than in samples of carotid artery adjacent to grafts $(1.16 \pm 0.39 \mathrm{mg} / \mathrm{g}$ wet weight, $P=.022)$ or in samples of unoperated saphenous vein from the same animals $(1.28 \pm 0.30 \mathrm{mg} / \mathrm{g}$ wet weight, $P=.034)$. The

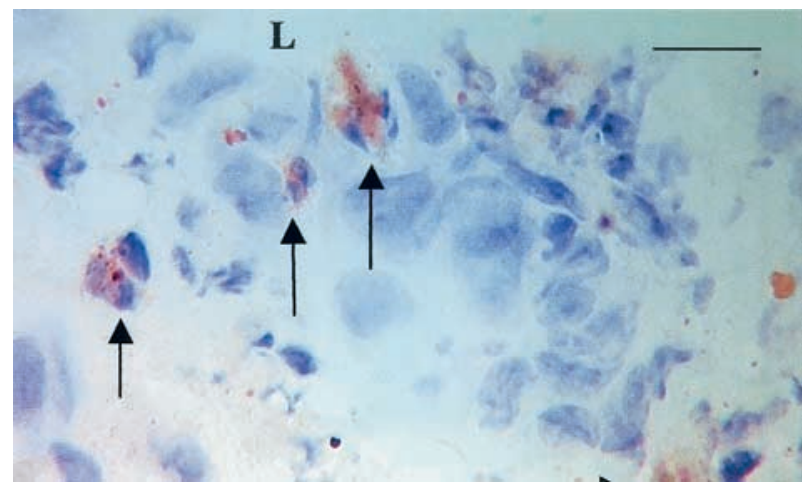

Figure 2. Foam-cell and macrophage accumulation in stented grafts. Oil Red $\mathbf{O}$ staining of a section of an unstented graft with hematoxylin counterstaining. Foam cells are indicated by arrows. The scale bar shows $10 \mu \mathrm{m}$. L, Lumen.

cholesterol levels in stented grafts was only $45 \%$ of that in unstented grafts $(P<.05)$ but was still approximately $70 \%$ greater than those in the adjacent artery and vein (both $P<$ $.02)$.

\section{Presence of Foam Cells}

Unstented grafts of cholesterol-fed pigs showed patchy accumulation of foam cells that could be stained with Oil Red $\mathrm{O}$ (Figure 2). Foam cells stained with the myeloid cell marker MAC 387 (not shown), indicating that they were most likely monocyte derived. Unstented grafts showed a significant $(P<.05)$ accumulation of foam cells, which accounted for $1.5 \% \pm 0.5 \%$ of neointimal cells $(n=6)$. No foam cells were detected in any of the 7 stented grafts.

\section{Expression of ICAM-1 and VCAM-1}

To begin to understand the mechanisms underlying the beneficial effect of the stent on foam-cell accumulation, we measured expression of the leukocyte adhesion molecules ICAM-1 and VCAM-1 by means of immunocytochemistry. ICAM-1 staining was confined to the endothelium and did not differ between stented and unstented grafts (results not shown). In unstented grafts a high level of VCAM-1 staining was evident in $53 \% \pm 8 \%$ of neointimal cells, including the luminal surface (presumably endothelial) cells (Figure $3, A)$. However, in stented veins the level of VCAM-1 was dramatically reduced (Figure 3,B). Nevertheless, weak staining was detectable in $19 \% \pm 3 \%$ of neointimal cells (n $=4, P<.05$ vs unstented grafts).

\section{Discussion}

The advantages of the pig model of vein grafting used here over the rabbit jugular vein ${ }^{23}$ or mouse vena cava ${ }^{24}$ models is a much closer match to the human saphenous vein in terms of lumen size and vessel-wall thickness. As a result, the size of the graft immediately postoperatively matches 


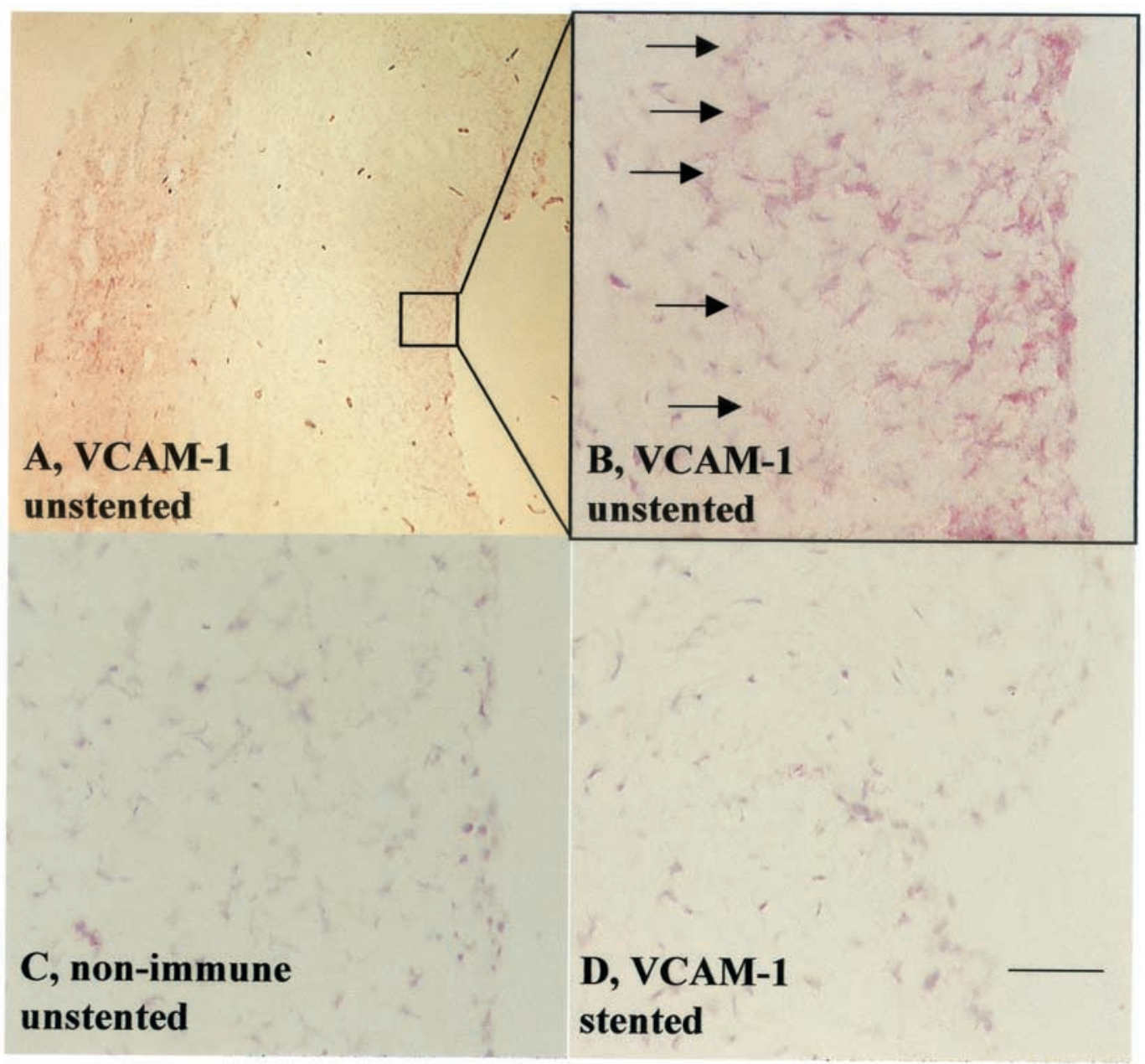

Figure 3. VCAM-1 staining in stented and unstented grafts: A, B, immunoalkaline phosphatase staining for VCAM-1 in an unstented graft; C, nonimmune staining in an unstented graft; D, immunoalkaline phosphatase staining for VCAM-1 in a stented graft. The scale bar shows $25 \mu \mathrm{m}$.

rather than being much larger than that of the carotid artery. ${ }^{18}$ Furthermore, the medial smooth muscle cells do not undergo extensive cell death ${ }^{16}$ and hence remain to make up the majority of the medial and neointimal cells in addition to ingress of adventitial cells. ${ }^{25}$ The major disadvantage of the pig model has been the relative difficulty of studying the effect of hypercholesterolemia, although one previous study reported the presence of Oil Red O-positive cells in venous, but not arterial, grafts in cholesterol-fed pigs. ${ }^{26}$ In a preliminary study we used a similarly cholesterol-rich diet without suet as an additional source of saturated fat. However, only a doubling of mean plasma cholesterol level was obtained $(2.3 \pm 0.4$ to $4.6 \pm 2.6 \mathrm{mmol} / \mathrm{L})$, which failed to achieve statistical significance. The magnitude of the response varied widely in individual pigs, with some animals not responding at all. Inclusion of $10 \%$ by weight of saturated fat significantly enhanced the hypercholesterolemia observed, although individual responses were still very variable, ne- cessitating the selection of animals before the operation. The relatively mild hypercholesterolemia produced is consistent with values in the pathophysiologic range in human subjects, rather than the 30 to $40 \mathrm{mmol} / \mathrm{L}$ levels often achieved in rabbit and mouse models.

The effect of external stenting to reduce neointimal and medial thickening and ameliorate lumenal encroachment is similar in magnitude to that previously described in normocholesterolemic pigs. ${ }^{14}$ These previous studies established that the effect of stenting was observed as early as 1 month after graft implantation and was sustained up to 6 months. ${ }^{16}$ We chose to study the effect of stenting at 3 months in this study because this period of cholesterol feeding has been commonly used to produce arterial lesions in rodent experiments. ${ }^{5,7}$ Also, given the very high cost of the large quantities of cholesterol-enriched diet necessary to feed pigs and their substantial weight gain, it was not feasible to prolong the experiment further. The relatively short period of hy- 
percholesterolemia in our pig studies compared with exposure over years in human subjects is a limitation to the interpretation of our results. Nevertheless, we found that even after 3 months there was an approximately 4-fold increase in the total cholesterol concentration within the unstented vein grafts compared with that seen in arteries and veins from the same animal. Furthermore, this correlated with the focal accumulation of foam cells, as previously reported, ${ }^{26}$ albeit in relatively small numbers. The diet did not induce the kind of gross atherosclerotic lesions produced by much higher cholesterol levels in rodents. Arguably, the pattern in our pig model is more consistent with the slow progress of atherosclerosis in human vein grafts.

Our results clearly show that external stenting with macroporous polyester velour decreased atherosclerosis in cholesterol-fed pigs. Although stenting with microporous polytetrafluoroethylene was previously shown in rabbits to reduce atherosclerotic lesion formation, ${ }^{10}$ this greatly increases neointima formation and reduces final lumenal size in both rabbit and pig vein grafts. ${ }^{12,27}$ The basis for the efficacy of the stent on neointima formation has been discussed in detail elsewhere. ${ }^{16}$ Briefly, because an oversized stent is effective, ${ }^{15}$ we have argued that the neoadventitia that forms between the stent and the graft, which eventually provides mechanical support to the graft, ${ }^{16}$ is of prime significance. Endothelial regeneration appears to be complete in both stented and unstented vein grafts. Nevertheless, stenting reduces the rate of smooth muscle cell proliferation, and this correlates with reduced production of platelet-derived growth factor. ${ }^{16}$ In addition, a more effective adventitial microvascular network develops when grafts are stented with macroporous polyester than in unstented grafts, and this does not occur when polytetrafluoroethylene is used as an external stent. ${ }^{13}$

We show here that the reduction of atherosclerosis by stenting is associated with a profound downregulation of the expression of VCAM-1. Increased VCAM-1 expression is strongly associated with atherosclerosis in rabbit and mouse models ${ }^{28,29}$ and is found in human atheroma. ${ }^{30}$ VCAM-1 is a marker for the earliest stages of atherosclerosis or even predilection for atherosclerosis. ${ }^{29}$ Moreover, from recent studies, VCAM-1 appears to be indispensable for atherosclerosis formation in the $\mathrm{ApoE}^{-1-}$ mouse. ${ }^{31}$ Therefore it seems likely that reduced VCAM-1 is causally related to the reduced foam-cell formation we observed after stenting, although other mechanisms might also be involved. For example, the pronounced adventitial network in stented grafts might reduce atherosclerosis by promoting passive permeation of cholesterol, although this remains to be demonstrated.

The stenting procedure used here is feasible in human subjects, and a clinical trial of this concept (the EXTENT trial) is presently ongoing. It will, however, seek only to determine whether stenting reduces total vessel-wall thickness after 6 months, as determined by means of intravascular ultrasonography. Because detectable atherosclerosis develops later, it is important to establish in experimental studies first what the likely effect of stenting will be. Our present study provides reassurance that the effect of stenting on late atherosclerosis is likely to be beneficial.

\section{References}

1. Campeau L, Enjalbert M, Lesperance J, Vaislic C, Grondin CM, Bourassa MG. Atherosclerosis and late closure of saphenous vein grafts. Sequential angiographic studies 2 weeks, 1 year, 5 to 7 years and 10 to 12 years after surgery. Circulation. 1983;68(Suppl):II-1-7.

2. Motwani JG, Topol EJ. Aortocoronary saphenous vein graft disease: pathogenesis, predisposition, and prevention. Circulation. 1998;97: 916-31.

3. Jeremy JY, Mehta D, Angelini GD. Pathophysiology and treatment of vein graft disease following coronary artery bypass graft surgery. $J$ Drug Dev Clin Pract. 1996;8:135-50.

4. Campeau L, Knatterud GL, Domanski M, Hunninghake DB, White $\mathrm{CW}$, Geller NL, et al. The effect of aggressive lowering of low-density lipoprotein cholesterol levels and low-dose anticoagulation on obstructive changes in saphenous-vein coronary-artery bypass grafts. N Engl J Med. 1997;336:153-62.

5. Mann MJ, Gibbons GH, Kernoff RS, Diet FP, Tsao PS, Cooke JP, et al. Genetic engineering of vein grafts resistant to atherosclerosis. Proc Natl Acad Sci U S A. 1995;92:4502-6.

6. Mannion JD, Ormont ML, Magno MG, O’Brien JE, Shi Y, Zalewski A. Sustained reduction of neointima with c-myc antisense oligonucleotides in saphenous vein grafts. Ann Thorac Surg. 1998;66:1948-52.

7. Ehsan A, Mann MJ, Dell'Acqua G, Dzau VJ. Long-term stabilization of vein graft wall architecture and prolonged resistance to experimental atherosclerosis after E2F decoy oligonucleotide gene therapy. J Thorac Cardiovasc Surg. 2001;121:714-22.

8. Mann MJ, Whittemorre AD, Donaldson MC, Belkin M, Conte MS, Polak JF, et al. Ex-vivo gene therapy of human vascular bypass grafts with E2F decoy: the PREVENT single centre randomised controlled trial. Lancet. 1999;354:1493-8.

9. Zwolak RM, Adams MC, Clowes AW. Kinetics of vein graft hyperplasia: Association with tangential stress. J Vasc Surg. 1987;5:126-36.

10. Batellier J, Wassef M, Merval R, Duriez M, Tedgui A. Protection from atherosclerosis in vein grafts by a rigid external support. Arterioscler Thromb. 1993;13:379-84.

11. Kohler T, Kirkman TR, Clowes AW. The effect of rigid external support on vein graft adaptation to the arterial circulation. J Vasc Surg. 1989;9:277-85

12. Violaris A, Newby A, Angelini G. Effect of external stenting on wall thickening in arteriovenous bypass grafts. Ann Thorac Surg. 1993;55: $667-71$.

13. George SJ, Izzat MB, Gadsdon P, Johnson JL, Yim APC, Wan S, et al. Macroporosity is necessary for the reduction of neoitnimal and medial thickening by external stenting of porcine saphenous vein bypass grafts. Atherosclerosis. 2001;155:329-36.

14. Angelini GD, Izzat MB, Newby AC. External stenting reduces early medial and intimal thickening in a pig model of arteriovenous bypass grafting. J Thorac Cardiovasc Surg. 1996;112:79-84.

15. Izzat MB, Mehta D, Bryan AJ, Reeves B, Newby AC, Angelini GD. The influence of external stent size on early medial and neointimal thickening in a pig model of saphenous vein bypass grafting. Circulation. 1996;94:1741-5.

16. Mehta D, George SJ, Jeremy JY, Izzat MB, Southgate KM, Bryan AJ, et al. External stenting reduces long term medial and neointimal thickening and platelet derived growth factor expression in a pig model of arteriovenous bypass grafting. Nat Med. 1998;4:235-29.

17. Cybulski M, Iiyama K, Li H, Zhu S, Chen M, Iiyama M, et al. A major role for VCAM-1 but not ICAM-1 in early atherosclerosis. J Clin Invest. 2001;107:1255-62. 
18. Angelini GD, Bryan AJ, Williams HMJ, Morgan R, Newby AC. Distention promotes platelet and leukocyte adhesion and reduces short-term patency in pig arteriovenous bypass grafts. J Thorac Cardiovasc Surg. 1990;99:433-9.

19. Angelini GD, Bryan AJ, Williams HMJ, Soyombo AA, Williams A, Tovey $\mathrm{J}$, et al. Timecourse of medial and intimal thickening in pig arteriovenous bypass grafts: relationship to endothelial injury and cholesterol accumulation. J Thorac Cardiovasc Surg. 1992;103:1093103.

20. Harrison AA, Stocker CJ, Chapman PT, Tsang YT, Huehns TY, Gundel RH, et al. Expression of vascular cell adhesion molecule-1 by vascular endothelial cells in immune, nonimmune inflammatory, reactions in the skin. J Immunol. 1997;159:4546-54.

21. Stocker CJ, Sugars KL, Yarwood H, Delikouras A, Lechler RI, Dorling A, et al. Cloning of porcine intercellular adhesion molecule-1 and characterization of its induction on endothelial cells by cytokines. Transplantation. 2000;70:579-86.

22. Kissane JM, Robins E. The fluorimetric measurement of deoxyribonucleic acid in animal tissues with special reference to the central nervous system. J Biol Chem. 1958;233:184-8.

23. Zwolak RM, Kirlman TR, Clowes AW. Atherosclerosis in rabbit vein grafts. Arteriosclerosis. 1989;9:374-9.

24. Zhou Y, Dietrich H, Yanhua H, Metzler B, Wick G, Xu Q. Mouse model of vein bypass graft arteriosclerosis. Am J Pathol. 1998;153: 1301-10.
25. Shi Y, O'Brien JE, Mannion JD, Morrison RC, Chung W, Fard A, et al. Remodeling of autologous saphenous vein grafts. The role of perivascular myofibroblasts. Circulation. 1997;95:2684-93.

26. Shi Y, Patel S, Davenpeck KL, Niculescu R, Rodriguez E, Magno $\mathrm{MG}$, et al. Oxidative stress and lipid retention in vascular graftscomparison between venous and arterial conduits. Circulation. 2001; 103:2408-13.

27. Kohler TR, Kirkman T, Clowes AW. Effect of heparin on adaptation of vein grafts to arterial circulation. Atherosclerosis. 1989;9:523-8.

28. Nakashima Y, Raines EW, Plump AS, Breslow JL, Ross R. Upregulation of VCAM-1 and ICAM-1 at atherosclerosis prone sites on the endothelium of ApoE-deficient mice. Arterioscler Thromb Vasc Biol. 1998;18:842-51.

29. Iiyama K, Hajra L, Iiyama M, Li HM, DiChiara M, Medoff BD, et al. Patterns of vascular cell adhesion molecule-1 and intercellular adhesion molecule-1 expression in rabbit and mouse atherosclerotic lesions and at sites predisposed to lesion formation. Circ Res. 1999;85:199207.

30. O'Brien KD, Allen MD, McDonald TO, Chait A, Harlan JM, Fishbein $\mathrm{D}$, et al. Vascular adhesion molecule-1 is expressed in human coronary atherosclerotic plaques. Implications for the mode of progression of advanced coronary atherosclerosis. J Clin Invest. 1993;92:945-51.

31. Cybulsky MI, Iiyama K, Li H, Zhu S, Chen M, Iiyama M, et al. A major role for VCAM-1 but not ICAM-1 in early atherosclerosis. J Clin Invest. 2001;107:1255-62. 